\title{
Measuring Clothing Color and Design Symbolism Preferences and Purchase Intentions of Asian Indian Females at Different Levels of Acculturation
}

\author{
Ann Beth Presley ${ }^{1}$ and Whitney Upchurch Campassi ${ }^{2}$ \\ ${ }^{1} 308$ Spidle Hall, Auburn University, Auburn, AL 36849, USA \\ ${ }^{2}$ Denver Institute of Art, Denver, CO 80202, USA \\ Correspondence should be addressed to Whitney Upchurch Campassi; wcampassi@gmail.com
}

Received 30 April 2013; Accepted 3 June 2013

Academic Editors: S. Coseri and X. Peng

Copyright (c) 2013 A. B. Presley and W. U. Campassi. This is an open access article distributed under the Creative Commons Attribution License, which permits unrestricted use, distribution, and reproduction in any medium, provided the original work is properly cited.

\begin{abstract}
The purpose of this study was to develop a reliable and valid instrument to measure color, design clothing preferences, and purchase intentions of Asian-Indian female consumers; secondarily, to determine if westernized clothes with Asian-Indian ethnic dress elements might be purchased more often than westernized clothing with design attributes primarily symbolic of American culture at different levels of acculturation. The instrument included a modified acculturation scale, limited demographics, and the developed Clothing Preferences and Purchase Intention Instrument. The instrument consisted of four components: Color Symbolism and Purchase Intention, Design Symbolism and Purchase Intention, Symbolic Attributes Scale, and Clothing Preference and Purchase Intention for Mainstream American versus Asian-Indian Inspired. All of the scales had high reliability. Of the 30 colors in the instrument, red, magenta, orange gold, yellow, cobalt blue, and purple were symbolic of Asian-Indian dress; hunter green, navy blue, baby blue, and blue were considered western colors. Neutral colors were eliminated. Nine of the 27 tunics in the instrument were highly indicative of Asian-Indian clothing; 11 were indicative of westernized clothing. Secondarily, Asian-Indians preferred and showed intent to purchase westernized clothing with colors and designs associated with their native country's traditional dress regardless of acculturation.
\end{abstract}

\section{Introduction}

Study of Asian Indian immigrants to the (USA) and their clothing preferences and purchase intentions is an important area of research. Immigrants from India are at their highest rates in history [1]. According to the USA census, in 2010 there were 2.9 million people in the USA that classified themselves as Asian Indians. They have a growth rate of $38 \%$ since 2000, the highest rate for any Asian country [1]. Almost $67 \%$ of all Indians have a bachelor's or higher degree (compared to $28 \%$ nationally and $44 \%$ on average for all Asian American groups). Almost 50\% of Asian Indian immigrants have graduate or professional degrees [2]. In addition, the median family income for this group is $\$ 113,095$ compared to $\$ 68,257$ for the median overall household income in the USA [3] giving this ethnic group significantly higher purchasing power than many other consumers. Studying the clothing preferences and purchase behavior of this segment of the population is beneficial in providing a selection of apparel appealing to this market.

In order to study an ethnic group as they move to the USA, one must first determine how well they have adapted to the culture. The extent of acculturation may determine if the immigrants adhere strictly to their cultural values, beliefs, and norms or if they decide to adopt the western dress; are their purchases based more on aesthetics or on the symbolism associated with their native culture? Research is needed to describe these individuals, their clothing preferences, and purchase intentions for clothing to determine if change occurs as the designated ethnic group acculturates in the United States. Since no instrument for measuring these variables existed, the purpose of this research was 


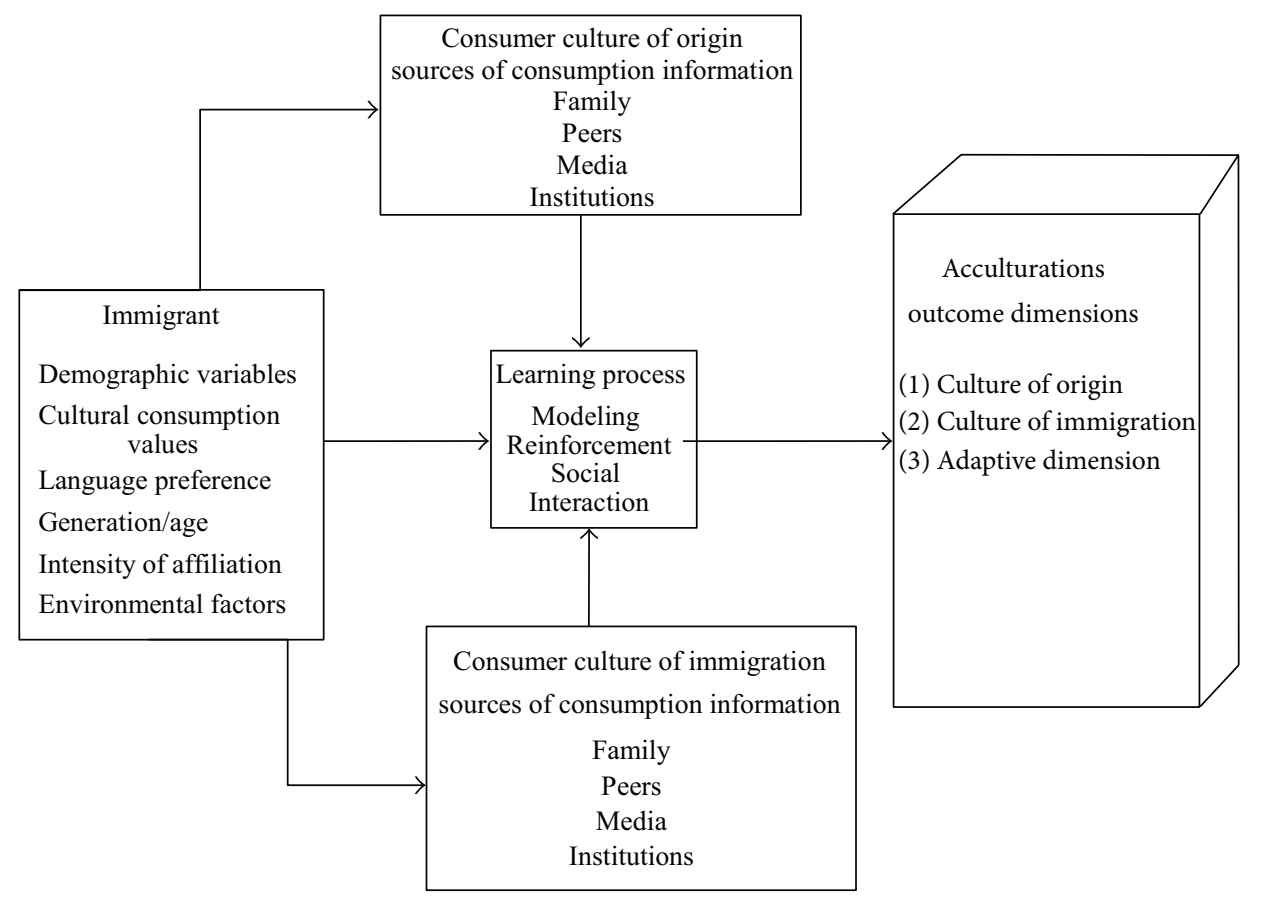

FIgURE 1: A model of Immigrant Consumer Acculturation [5, page 113].

to develop an appropriate instrument for measuring the clothing preferences and purchase behavior of female Asian Indian immigrants at different of acculturation.

For the purposes of this study, acculturation indicates the method/manner by which individuals adopt the values, beliefs, and norms of a culture different from the one in which they grew up. As individuals acquire more of the traits of the new culture, they may eventually lose some or all of the traits of their native culture, or they maintain part of their original culture while adding characteristics of the new culture, which is known as bidirectional acculturation [4].

Theory. The theoretical foundation of this research is based on Penaloza's [5] model of Immigrant Consumer Acculturation (see Figure 1). Much of the research finds several stages of acculturation. According to Penaloza [5], in the first stage of acculturation, the immigrant is fascinated by the new culture; the second stage is typified by a hostile attitude toward the new culture; in the third stage the individual acquires some of the cultural skills and knowledge of the host culture; and in stage four, cultural adjustment has occurred and the individual becomes integrated into the new culture.

As acculturation advances, individuals find cultural or behavioral features similar to the dominant culture. Then, integration occurs where the cultural identity of the minority culture is maintained, with a positive relationship between the dominant culture and the minority culture. In consumer acculturation, cultural adaptations occur, generally in one of two ways-separation, the retention of the culture of origin apart from the host culture, or rejection of both the host culture and the culture of origin [5]. On the other hand, integration or cultural adjustment occurs because the individual now has confidence in his/her ability to function in the new culture [6].

Berry [7] found that acculturation could be categorized into four levels: (a) assimilation occurs when an individual adopts the new culture, leaving behind all beliefs, values, identities, and so forth from one's own culture, (b) separation occurs when an individual chooses to withdraw from interactions with the new culture and holds onto one's ethnic identity, (c) integration occurs when there is an interest in preserving one's ethnic identity and, also, interacting with the new culture, and (d) marginalization occurs when one chooses to have little contact with the new culture. Each one of these modes will have some sort of effect on what influences consumers clothing choices. If an immigrant adopts a new culture (assimilation), that person's higher cultural values or ethnic identity will have little impact on the clothing chosen, and choices will be based, primarily, on aesthetic preferences. On the other hand, an immigrant categorized in the separation or marginal phase of acculturation will choose clothing based on symbolic attributes of the culture of origin.

Integrated immigrants are more likely to search for a sense of completeness as they juggle two culture's lifestyles on a daily basis. Wicklund and Gollwitzer's [8] Symbolic SelfCompletion Theory explains that people needing to fill some void in their life will self-define and relate to symbols that hold some meaning to them, as these symbols help them to feel complete. Visible symbols such as patterns of dress, ethnic dress, and appearance are ways of self-symbolizing. Clothing is an extrinsic factor that reveals an individual's environment by allowing outsiders to make reference to the individual's intrinsic traits, such as ethnicity [9]. 


\section{Review of Related Literature}

The growth of the Asian Indian population in the USA brings new market opportunities for the apparel industry. Overall, this is an affluent group of consumers, thus making it a potentially profitable target market for apparel manufacturers and retailers. It makes sense to look at how their acculturation process could help distinguish their preferences for westernized clothing symbolic of their Asian Indian culture. Some immigrants choose to preserve the beliefs and values of their native culture, while others begin to acculturate and take on some of the host country's beliefs and values, which will possibly alter their buying behavior [10]. While acculturating into a new culture, individuals must also self-define by using tangible objects that hold symbolic meanings to complete themselves. It has been found that many Asian Indians desire to keep strong ties with their home culture and preserve their ethnic identity [11]. In recent years, there has been an emerging market of consumers in search of ethnicallyinspired apparel [12].

Maintaining a strong ethnic identity is important in a collectivist society, such as India. The collectivist society stresses human interdependences and focuses on the community and society as a group. However, many Asian Indians find themselves balancing Indian culture with American culture each day [13]. Even though the westernized market in India is growing, Rajagopalan and Heitmeyer [14] found traditional clothing remains popular in India, even though the westernized clothing market in the country is growing. Therefore, it could be generalized that as Asian Indians move to the United States they choose Asian Indian traditional dress as a form of self-definition unless or until they are acculturated. On the other hand, these immigrants may prefer to wear westernized clothing that has design attributes that are symbolic of their culture. If fully assimilated into the new culture, immigrants will disregard all ethnic ties and become completely westernized. Alternatively, integrated immigrants will keep intact their ethnic identity while interacting with a new culture, attempting to keep a balance between their home culture and their new culture. However, if they choose to reject acculturation, then they will remain separated from the new culture and retain all the cultural values, beliefs, and norms with no room for persuasion into the new culture.

Consumer behavior researchers now recognize multiculturalism as a phenomenon which examines cultural pluralism. A bidimensional model measures the immigrant's level of acculturation based on the influences of two cultures on the individual. This bidimensional model examines the degree to which an individual retains one's culture and/or ethnic identity, as well as the degree to which one adapts to the new culture. Cleveland and Laroche [4] have found that immigrants are less likely to assimilate into the new culture; instead they tend to integrate, allowing themselves to identify with more than one culture, as well as alternating between two cultures depending on the social environment/setting. Integration and marginalization are more collectivist forms of adapting than assimilation since each level retains the individual's cultural values, while interacting with a new culture [15]. Assimilation is more reflective of an individualistic society, where the focus is on individual independence and self-reliance.

Do immigrants prefer to purchase westernized clothing whose design details are symbolic of the details of their culture's clothing? For example, when purchasing clothing an Asian Indian may be more attracted to a clothing item with vibrant colors, beading, embroidery, or intricate design motifs since these are typical design details of traditional Indian dress. Perhaps the item is a westernized piece having attributes that are aesthetically pleasing to this specific cultural group because they are symbolic to the individual and his/her home culture.

Ogden et al. [16] proposed that the level of acculturation will moderate purchase outcomes of immigrants. For example, individuals with a low level of acculturation are more likely to purchase items that hold symbolic meanings with their native culture. Conversely, individuals with a higher level of acculturation are more likely to seek purchases that hold little symbolic meaning with their culture and are found to be more aesthetically pleasing to the consumer.

Rajagopalan and Heitmeyer [14] looked at consumer levels of involvement in Indian ethnic apparel and contemporary American clothing. The focus of the study was on how Asian Indians in a new culture viewed products from their original culture throughout stages of acculturation. The respondents were asked to identify which of two types of apparel they preferred. These researchers found that some Asian Indians chose to continue wearing traditional Asian Indian apparel, while others chose American clothing. The individuals who chose American apparel were more likely to begin wearing Indian ethnic apparel again once they felt acculturated into the new culture. Rajagopalan and Heitmeyer [14] also found that those Asian Indians with low levels of acculturation had higher levels of involvement with ethnic Indian apparel. Those that exhibited moderate levels of acculturation to the USA became less immersed in Indian ethnic culture and clothing. Interestingly, this study found that consumers with "mostly moderate" and "high" levels of acculturation were more involved with the selection and purchasing of ethnic Indian apparel.

For the purpose of this study, it is presumed that Asian Indians prefer westernized clothing that reflect the colors, designs, and symbolic attributes (e.g., beading, embroidery, tie-dye, and intricate motifs) of their traditional dress and their culture. As Asian Indians adapt to their new culture, it is not necessarily true that these immigrants will disregard all aspects of dress that are important to their home culture. It is assumed that integrated or even moderately acculturated Asian Indians will equally prefer clothing with contemporary westernized designs, or westernized clothing with Indian ethnic designs.

2.1. Purpose of the Study. The purpose of this study was to develop an instrument to measure color and design clothing preferences and purchase intentions of Asian Indian female consumers and to test the reliability and validity of the instrument. Secondary purposes were to determine if westernized clothes with Asian Indian ethnic dress elements, 
such as design details and color attributes, may be purchased more often than westernized clothing with design attributes that are primarily symbolic of American culture and to investigate possible relationships between a culture new to the United States and their clothing preferences and purchase intentions at different levels of acculturation. Researching a collectivist subculture attempting to acculturate into an individualistic culture will help determine if the collectivist group is more likely to purchase westernized clothing having attributes symbolic to their ethnic identity or to purchase westernized clothing with mainstream American attributes.

Consumers who identify themselves as multicultural describe themselves as being integrated with the host culture and their home culture. This group of immigrant's consumption patterns can be identified as being mixed between the two cultures. However, assimilated immigrant's consumption patterns are more like the host culture. Khairullah's and Khairuulah's [17] study found that those Asian Indians with low and moderate levels of acculturation would more likely respond to fashion advertisements with ethnic Indian themes as opposed to those with traditional American themes, whereas those Asian Indians that are highly acculturated were more likely to be reached with, and respond to, western style advertisements.

With the growth in an affluent Asian Indian population, with enhanced purchasing power, it is important for retailers to be acquainted with a new market segment they can target. This study is significant because it provides an instrument for measuring Asian Indian clothing preferences and purchase intentions, and it begins to fill a gap in the literature which identifies how Asian Indians view clothing choices as they adapt to a new culture.

2.2. Sample. A purposive sample was drawn from female Asian Indian immigrants who were members of the Hindu Temple of a large southeastern city. A table was set up at the entrance of the Temple, and women were asked to participate as they were entering the Temple. There were 25 respondents who agreed to participate, and each was given a letter explaining the purpose of the study and assuring them of anonymity. In order to accurately describe the participants, selected demographics were collected: gender, age, marital status, religious affiliation, completed level of education, major, and length of time in the United States. Questions regarding social group and income were omitted since previous studies have found these variables to be a sensitive topic among this ethnic group [18].

2.3. Acculturation. Khairullah and Khairuulah [18] obtained data from Asian Indian students living in America in order to study levels of consumer acculturation. The instrument measures behavioral acculturation of Asian Indians by means of an adapted version of Szapocznik et al's [19] scale used to measure Cuban's acculturation levels which consisted of 24 items. Szapocznik et al's [19] scale was developed to seek information about first generation immigrants to the United States in the late 1970s. Khairullah and Khairuulah's [18] version of the scale looked at 20 items, which have proven reliable and valid with a Cronbach's alpha coefficient of .97, and the scale has been used by a number of researchers seeking information on Asian Indian acculturation. For the present study, Khairullah and Khairuulah's [18] Behavioral Acculturation scale was modified slightly by adding two questions that pertained to clothing preferences.

\subsection{Development of the Clothing Preferences and Purchase} Intention Instrument. The colors, designs, and symbolic attributes characteristic of Asian Indian and American apparel were researched, identified, and, then, verified by a panel of clothing specialists who were highly knowledgeable about clothing of both Asian Indians and Americans. The instrument consisted of four components: (1) Color Symbolism and Purchase Intention Scale, (2) Design Symbolism and Purchase Intention Scale, (3) Symbolic Attributes Scale, and (4) Clothing Preference and Purchase Intention for Mainstream American versus Asian Indian Inspired Scale. The latter two scales were included to verify assumptions made in regard to the first two scales. All answers were selfreported by the respondents.

Articles of clothing were chosen as accurate representations of mainstream westernized clothing, some with standard American attributes and others with Asian Indian inspired details. Pictures of 27 garments were used as stimuli to evoke responses in the Design Symbolism and Preference Scale. In addition, 30 colors were chosen to evoke responses of colors reflective of Asian Indian ethnic clothing and those reflective of mainstream American clothing. The Scales for both the Color and Design Symbolism and Purchase Intention Scales were structured in a way that each respondent could check as many colors or designs as she felt applied. Statements such as, "Color A or Article A is symbolic of Asian Indian dress" and "I tend to purchase Color A or Article A" were used for determining which colors and designs were symbolic of Asian Indian traditional or mainstream American dress, as well as which colors the participants had a greater tendency to purchase. Both the colors and garment images were mounted on visual stimuli cards. A panel of experts was consulted to verify the authenticity of the colors and clothing items.

The Color Symbolism and Purchase Intention Scale. A set of 30 colors were identified as characteristic of either Asian Indian or American clothing. Each color was assigned an identifying letter, and they were mounted on stimulus cards (10 colors per card). The respondents were asked to use the visual stimuli to choose the articles of clothing they felt had color features symbolic of mainstream Asian Indian clothing or American clothing. Then, they were asked to choose which articles of clothing they had a tendency to purchase. The original color scale is included in Figure 2.

The Design Symbolism and Purchase Intention Scale. The tunic or kurta originated in India, and it has become mainstream in western fashion. A total of 27 tunics were selected as accurate representations of mainstream westernized clothing with either Asian Indian attributes or standard American attributes. A set of three stimulus cards were developed, each 


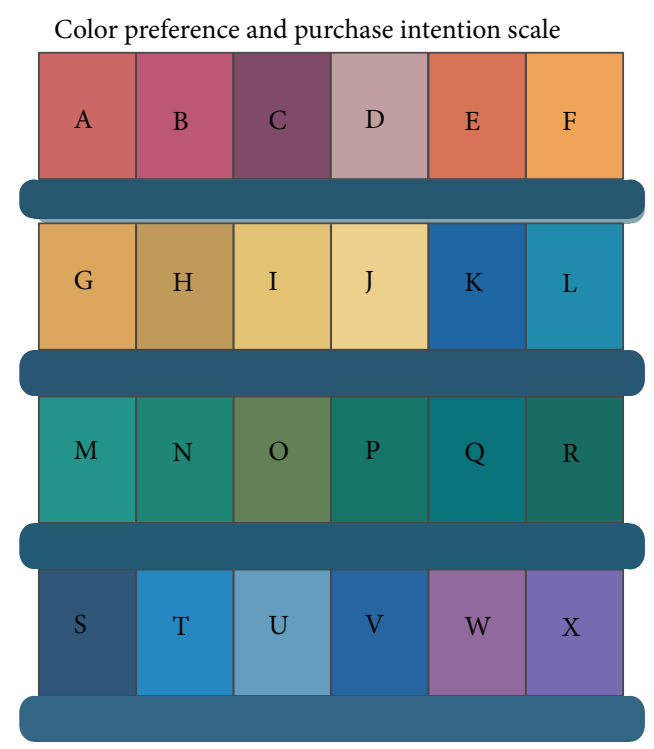

FIGURE 2

with images of nine tunics (each assigned an identifying letter). Respondents were asked to identify the images that were symbolic of Asian Indian traditional or mainstream American clothing and which ones they were more likely to purchase.

The Symbolic Attribute Scale. This scale permitted clarification of which design attributes, such as intricate surface motifs and embellishments, the respondents thought were symbolic of Asian Indian traditional dress or mainstream American dress. Statements such as "Embroidery is symbolic of Asian Indian traditional dress" or "Embroidery is symbolic of mainstream American dress" were answered by choosing from 1 (strongly agree) to 5 (strongly disagree) on a 5 -point Likert-type scale. This verbal scale was designed to verify that the assumptions made about Asian Indian traditional dress were correct and thus to ensure validity of the two previous other scales.

The Clothing Preference and Purchase Behavior for AsianInspired Clothing and Mainstream American Clothing Scale. Eight questions were designed to determine preferences for Asian American clothing versus mainstream American clothing, and eight questions assessed purchase behavior. Respondents used a 1 (strongly agree) to 5 (strongly disagree) on a 5-point Likert-type scale to answer the 16 questions, such as "I prefer mainstream American clothing with designs and embellishments associated with Asian Indian clothing." Or "I purchase mainstream American clothing with designs and embellishments associated with Asian Indian clothing." This scale was used to determine the extent to which the respondents preferred and purchased clothing associated with Asian Indian inspired features versus clothing with westernized features. Also, the scale helped to verify previous assumptions.
2.5. Methods and Analysis. Levels of behavioral acculturation were identified using the Khairullah and Khairuulah's [18] 20 -item survey with a reliability of $a=0.97$, plus the two clothing-related items added by the researcher, to measure Asian Indian behavioral acculturation. The scale consisted of twenty-two Likert-type questions. Possible answers for each question were as follows: (1) Indian all of the time; (2) Indian most of the time; (3) Indian and American equally; (4) American most of the time; (5) American all of the time [18]. The acculturation scores for this study were divided into two categories: low and high acculturation levels based on mean scores calculated for each respondent. Respondents were, then, grouped into either low or high acculturated categories. Acculturation scores ranging from 1.0 to 2.99 were affiliated with low acculturation individuals. Highly acculturated individuals had scores ranging from 3.0 to 5.0 based on the 1-5 Likert-type scale.

Data for clothing-related scales were collected, coded, and analyzed using descriptive statistics and Cronbach's alpha to assure a reliability coefficient of $\alpha \geq 0.70$. The four component scales of the clothing preferences and purchase intention instrument were analyzed for parsimonious relationships and to determine if the instrument adequately measured construct validity, that is, if it measured what it was supposed to measure [20]. Relationships between demographic variables, acculturation levels, and clothing preferences were examined by Pearson's correlation analysis [21]. Data were further examined to refine the instrument.

Frequency tables were used to determine which colors and designs hold the most meaning to the Asian Indian sample. The frequency tables allowed the researcher to categorize the colors and designs as symbolic of Asian Indian traditional dress or mainstream American dress. A reliability analysis was run to determine the Cronbach's alpha to ensure that measures were reliable for the Likert-type scales.

Cross-tabulations, a statistical process that forms twoway and multiple-way tables were created for the visual stimuli sections of the questionnaire. The Color and Design Preference and Purchase Intentions Scales were cross-tabulated with higher and lower levels of acculturation. Percentages were calculated from the answers of each respondent to determine if level of acculturation influenced color and design preferences and purchase intentions.

\section{Results and Discussion}

3.1. Description of Sample. The demographic data provided a description of the sample and are presented in Table 1. Of the 25 respondents, $20(80 \%)$ were married and the majority to spouses of the same ethnic origin (90\%). Sixty-four percent were between the ages of 30 and 49. A total of 72 percent of respondents had a bachelor's degree or some graduate study for their education level. The majority of the respondents had lived in the United States for 11-20 years (32\%). However, a total of 48 percent (2-3 years, $28 \%$; $4-10$ years, $20 \%$ ) had lived in the United States between 2 and 10 years. These percentages correspond with the rapid growth of this particular group of immigrants in the United States over the past decade [1]. 
TABLE 1: Demographic Statistics.

\begin{tabular}{|c|c|c|}
\hline Demographics & $f$ & $\%$ \\
\hline \multicolumn{3}{|l|}{ Marital status } \\
\hline Married & 20 & $80 \%$ \\
\hline Single & 5 & $20 \%$ \\
\hline \multicolumn{3}{|l|}{ Divorced } \\
\hline \multicolumn{3}{|l|}{ Widowed } \\
\hline \multicolumn{3}{|l|}{ Spouse ethnicity } \\
\hline Indian & 18 & $72 \%$ \\
\hline Other & 2 & $8 \%$ \\
\hline Not applicable & 5 & $20 \%$ \\
\hline \multicolumn{3}{|l|}{ Age } \\
\hline$<20$ & 3 & $12 \%$ \\
\hline $20-29$ & 4 & $16 \%$ \\
\hline $30-39$ & 8 & $32 \%$ \\
\hline $40-49$ & 8 & $32 \%$ \\
\hline $50-59$ & 2 & $8 \%$ \\
\hline \multicolumn{3}{|l|}{ Religious affiliation } \\
\hline Hindu & 25 & $100 \%$ \\
\hline \multicolumn{3}{|c|}{ Level of education completed } \\
\hline High school & 1 & $4 \%$ \\
\hline Some bachelor's & 3 & $12 \%$ \\
\hline Bachelor's & 7 & $28 \%$ \\
\hline Some graduate & 5 & $20 \%$ \\
\hline Master's & 6 & $24 \%$ \\
\hline Some doctoral & 2 & $8 \%$ \\
\hline Doctorate & 1 & $4 \%$ \\
\hline \multicolumn{3}{|c|}{ Length of stay in United States } \\
\hline$<2$ years & 1 & $4 \%$ \\
\hline $2-3$ years & 4 & $16 \%$ \\
\hline $4-10$ years & 7 & $28 \%$ \\
\hline $11-20$ years & 5 & $20 \%$ \\
\hline$>21$ years & 8 & $32 \%$ \\
\hline
\end{tabular}

3.2. Acculturation. The acculturation scale was found to be highly reliable for the participants in this study with a Cronbach's alpha of 0.951 . In regard to the influence of acculturation level on color and design symbolism, the acculturation scores were clustered in the middle of the scale. Thus, we can speculate that the majority of the Asian Indian participants were marginalized or integrated in regard to acculturation. The latter group may be bi-cultural or at least most had reached the assimilation level of acculturation.

Color Symbolism and Purchase Intentions Instrument. The 30 colors presented to participants, six neutral colors (grey, beige, cream, brown, white, and black) were not found symbolic of Asian Indian or mainstream American clothing and, therefore, were deleted even though purchase intent was found for them. This left colors reflective of both cultures in the scale. In addition, the colors with the lowest response rate were rejected. Several colors had frequencies of $50 \%$ or higher as being symbolic of Asian Indian dress. These colors, red, magenta, orange gold, yellow, cobalt blue, and purple, were identified as symbolic of Asian Indian traditional dress. For each color found symbolic of Asian Indian traditional dress, the respondents indicated purchase intent. All colors that the participants indicated as Asian Indian colors were the colors that the researchers kept as Asian Indian colors.

The remaining colors, Mauve, Gold, Yellow Beige, Light Teal, Kelly Green, Emerald Green, Dark Teal, Hunter Green, Navy Blue, Baby Blue, and Blue, were categorized as western colors. All of these colors were selected by the participants as colors representative of westernized dress had been preidentified as such.

Design Symbolism and Purchase Intention Scale. Each respondent could indicate which tunic images on the three stimulus cards she felt had Asian Indian design/style features or westernized features, as well as indicting her intent to purchase. Findings were reflective of what the Asian Indian consumers found to be symbolic of their culture's traditional dress and their purchase intentions. Nine of the 27 articles were considered highly indicative of Asian Indian clothing by a minimum of $48 \%$ of the respondents. Additionally, six articles were considered symbolic by $32-44 \%$ of the sample. Eleven of the articles were considered indicative of westernized clothing by a minimum of $48 \%$ of the sample. Nine other articles were also considered characteristic of westernized clothing by $32-44 \%$ of the sample. However, six articles appeared on both lists, suggesting that some participants associated those articles with Asian Indian clothing while others thought they were more closely aligned with American culture. Consequently, these articles were omitted.

Symbolic Attributes Scale. The data from this scale were used that assumptions made about design in the Design Symbolism and Purchase Behavior Scale were correct. The results verified that surface patterns, details, and embellishments chosen to symbolize Asian Indian traditional dress did distinguish them from those chosen to symbolize mainstream American dress. These verified assumptions for the previous scale and this portion of the pretest were omitted from the final survey, once the researcher determined the reliability of the scale.

Clothing Preferences and Purchase Intentions for Asian Indian Inspired versus Mainstream American Clothing. Eight items in this scale pertained to Asian Indian inspired American clothing and had a Cronbach's alpha of 0.911. Within this scale, the four questions that examined preferences had a Cronbach's alpha of 0.831 , while the purchase intention reliability was 0.854 . The eight statements about preferences and purchase intentions for mainstream American clothing with colors, surface patterns, and embellishments common to western culture had a Cronbach's alpha of 0.871 . The four preferences statements had a Cronbach's alpha of 0.749 , while the four that examined purchase intentions had a reliability coefficient of 0.818 .

The eight statements about purchase intentions and preferences for mainstream American clothing with Asian Indian design influences, such as color, surface patterns, 
and embellishments common to Asian Indian culture, had a Cronbach's alpha of 0.911 . The four preference statements in the scale were found to be reliable with a Cronbach's alpha of 0.831 , while the purchase intentions reliability was 0.854 . Therefore, this scale had high reliability and validated the assumptions for the Clothing and Design Symbolism Preferences and Purchase Intentions Scales. It was eliminated from the final instrument.

\section{Conclusions}

The purpose of this research was to develop an instrument to measure color and design clothing preferences and purchase intentions of Asian Indian/Americans and to test the reliability and validity of the developed instrument. The first and second components of the instrument were tested and found to have high reliability. The results of the third and fourth components of the instrument provided evidence of validity of the first and second components. The Clothing Color and Design Symbolism Preferences and Purchase Intention Instrument was then refined based on testing the four components of the instrument and eliminating certain colors and designs, as well as components three and four of the original instrument.

In regard to the influence of acculturation on color and design clothing preferences and purchase intent, the majority of the participants scored in the midrange of the acculturation scale. Asian Indians preferred and showed intent to purchase westernized clothing with colors associated with their native country's traditional dress whether or not they were closer to the high end of the acculturation scale. This supports the idea that their heritage is an important factor in their lives, and they embrace it when adapting to the host culture. This is not to say that the same individuals do not also prefer or purchase clothing with mainstream American features. Many of these women are accustomed to their traditional dress, which is a work of art, and they may not want to part ways with it. So, they purchase westernized clothing that incorporates the colors, attributes, surface patterns, and other details mostly like the ones of their home country. These results were secondary to the primary purpose of the development and testing of the Clothing Color and Design Symbolism Preferences and Purchase Intention Instrument.

4.1. Limitations and Future Research. Several limitations were present in this study, which should be considered when examining the findings. The purposive sample was limited in size and included only Asian Indian females living in the southeastern area of the United States. Therefore, the findings cannot be generalized to the whole population of Asian Indian females in the United States or even one location.

Another limitation was that all respondents were of the Hindu religion. Previous research has found that different colors in the Indian culture are representative of each religion, and some colors are not recognized at all by some religions. Therefore, if this study was duplicated with Asian Indians of another religion, the findings might yield different results.
Comparing clothing preferences to purchase intentions, high acculturated respondents who preferred mainstream clothing with Asian Indian inspired attributes indicated that they also had a tendency to purchase clothing with Indian attributes. Purchase intentions for colors between high and low acculturated individuals were very similar which may be due to the fact that the majority of the respondents clustered around the midpoint of the acculturation scale. Future researchers could examine this further by seeking a more diverse sample of the Asian Indian population. In conclusion, this study provided an evaluative instrument with validity and reliability for determining Asian Indian consumers clothing preferences and purchase intentions. Information obtained by using the instrument with Asian Indians would be useful to manufacturers and retailers in this country. The research also contributed, incidentally, to the gap in the literature regarding Asian Indian clothing preferences and intentions to purchase, but findings should be considered in the context of the study limitations.

\section{References}

[1] E. M. Hoefel, S. Rastogi, M. O. Kim, and H. Shahid, “The Asian population: 2010," 2010 Census Briefs. United States Census Bureau, http://www.census.gov/prod/cen20101/briefs/c20br-11 .pdf.

[2] "How Asian Indians experience America," 2007, http://www .boston.com/, http://www.boston.com/jobs/diversityspring07/ articles/2007/04/18/how_asian_indians_experience_america/.

[3] A. Mathu, "Consumer acculturation in the age of globalization: a study of first-generation Indian immigrants in the United States," Journal of International Marketing, vol. 24, no. 3, pp. 372384, 2012.

[4] M. Cleveland and M. Laroche, "Acculturaton to the global consumer culture: scale development and research paradigm," Journal of Business Research, vol. 60, no. 3, pp. 249-259, 2007.

[5] L. N. Penaloza, "Immigrant consumer acculturation," Advances in Consumer Research, vol. 16, pp. 110-118, 1989.

[6] K. Oberg, "Cultural shock: adjustment to new cultural environment," Practical Anthropologist, vol. 7, pp. 177-182, 1960.

[7] J. Berry, "Psychology of acculturation," in Nebraska Symposium on Motivation, J. J. Berman, Ed., vol. 3, pp. 201-234, Lincoln University Press, Lincoln, Neb, USA, 1990.

[8] R. Wicklund and P. Gollwitzer, Symbolic Self-Completion, Lawrence Erlbaum Associates, Hillsdale, NJ, USA, 1982.

[9] J. Forney and N. Rabolt, "Ethnic identity: its relationship to ethnic and contemporary dress," Clothing and Textile Research Journal, vol. 4, no. 2, pp. 1-7, 1985.

[10] D. Khairullah, F. Tucker, and C. Tankersley, "Acculturation and immigrant consumers' perceptions of advertisement: a study involving Asian-Indians," International Journal of Commerce \& Management, vol. 6, no. 3-4, pp. 81-104, 1996.

[11] S. D. Dasgupta, "Gender Roles and Cultural Continuity in the Asian Indian Immigrant Community in the U.S," Sex Roles, vol. 38, no. 11-12, pp. 953-974, 1998.

[12] M. Eckman, "Purchase decision behavior for and satisfaction with apparel among U.S. retail buyers and consumers of ethnic apparel," Fashion Information and Technology, vol. 2, pp. 49-58, 2005. 
[13] J. Aaker, V. Benet-Martínez, and J. Garolera, "Consumption symbols as carriers of culture: a study of Japanese and Spanish brand personality constructs," Journal of Personality and Social Psychology, vol. 81, pp. 249-264, 2001.

[14] R. Rajagopalan and J. Heitmeyer, "Ethnicity and consumer choice: a study of consumer levels of involvement in Indian ethnic apparel and contemporary American clothing," Journal of Fashion Marketing and Management, vol. 9, no. 1, pp. 83-105, 2005.

[15] J. Berry, "Conceptual approaches to acculturation," in Acculturation: Advances in Theory, Measurement, and Applied Research, K. Chun, P. Balls-Organista, and G. Marin, Eds., pp. 17-37, APA Press, Washington, DC, USA, 2007.

[16] D. Ogden, J. Ogden, and H. Schau, "Exploring the impact of culture and acculturation on consumer purchase decisions: toward a microcultural perspective," Academy of Marketing Science Review, vol. 3, pp. 1-22, 2004.

[17] D. Khairullah and Z. Khairuulah, "Relationships between acculturation, attitude, toward the advertisement, and purchase intentions of Asian-Indian immigrants," International Journal of Commerce \& Management, vol. 9, no. 3-4, pp. 46-65, 1999.

[18] D. Khairullah and Z. Khairuulah, "Behavioural acculturation and demographic characteristics of Asian-Indian immigrants in the United States of America," International Journal of Sociology and Social Policy, vol. 19, no. 1-2, pp. 57-80, 1999.

[19] J. Szapocznik, M. A. Scopetta, W. Kurtines, and M. A. Aranalde, "Theory and measurement of acculturation," Interamerican Journal of Psychology, vol. 12, pp. 113-130, 1978.

[20] J. C. Nunnally and I. H. Bernstein, Psychometric Theory, McGraw-Hill, New York, NY, USA, 3rd edition, 1994.

[21] D. Reedy, The relationship of the ethnic identity, acculturation, and psychological adjustment among Asian Indian immigrants [Doctoral Dissertation], Loyola University, Kansas City, Mo, USA, 1996. 

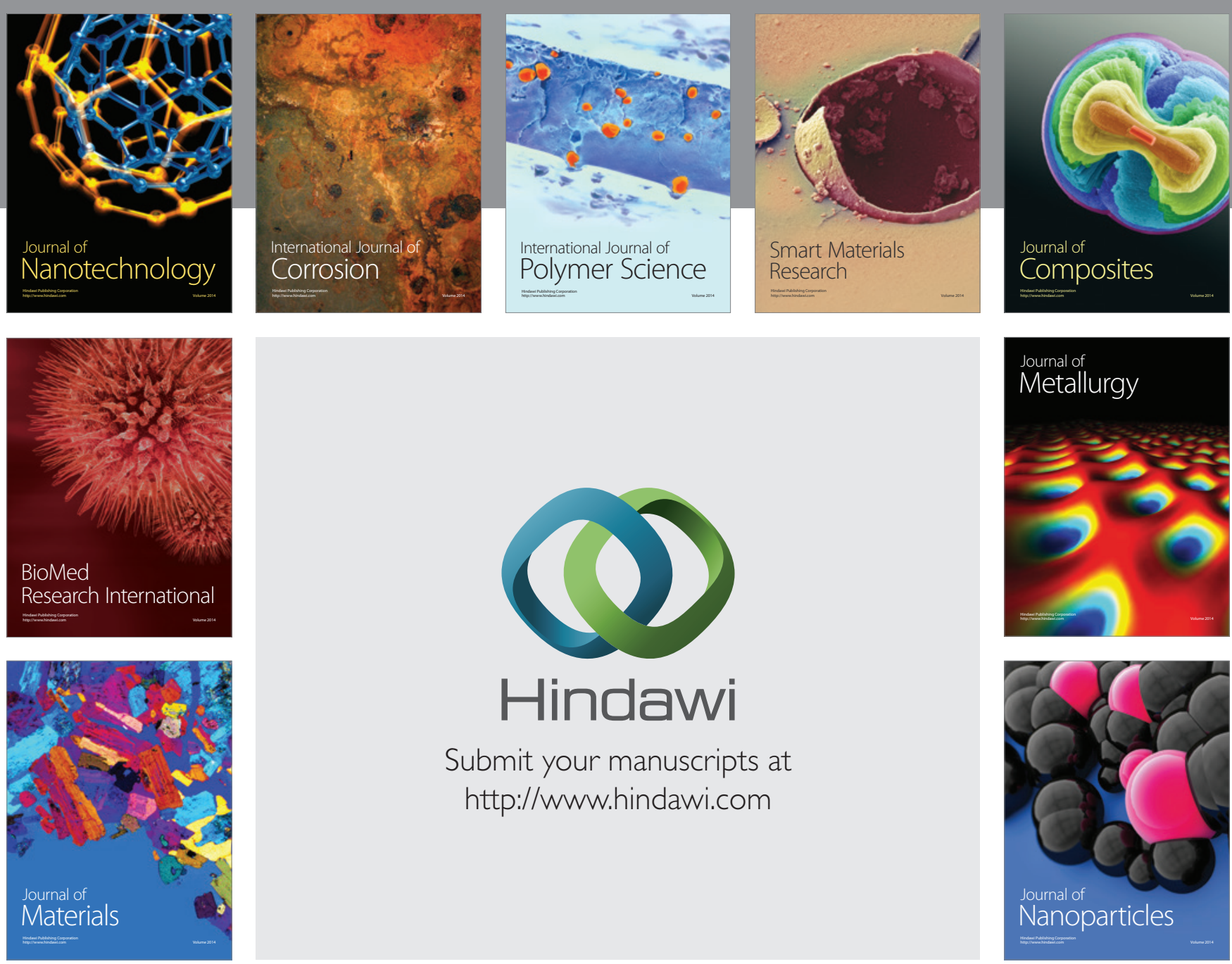

Submit your manuscripts at http://www.hindawi.com
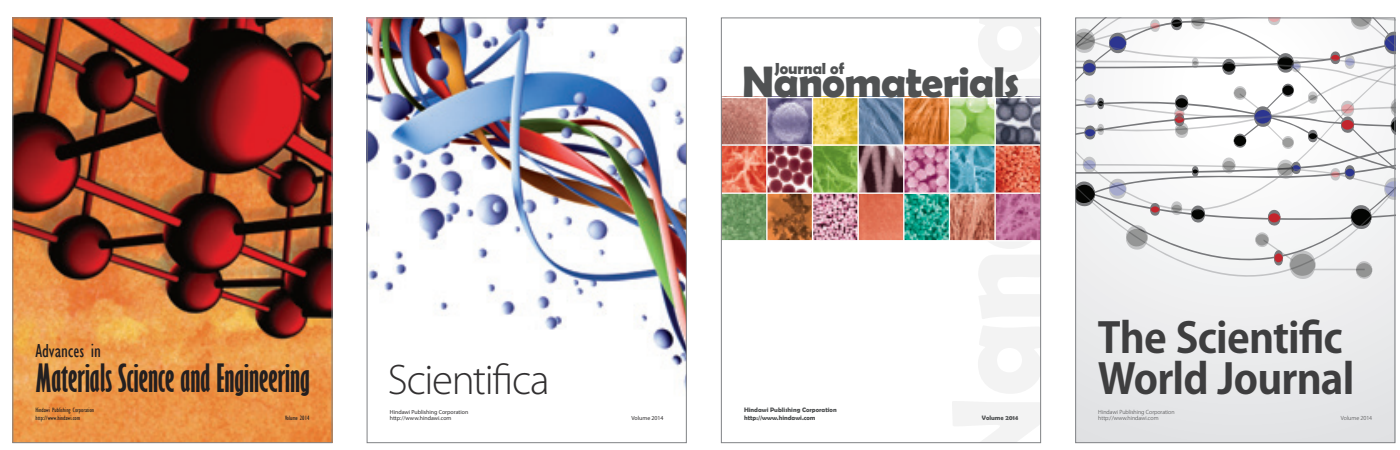

\section{The Scientific World Journal}
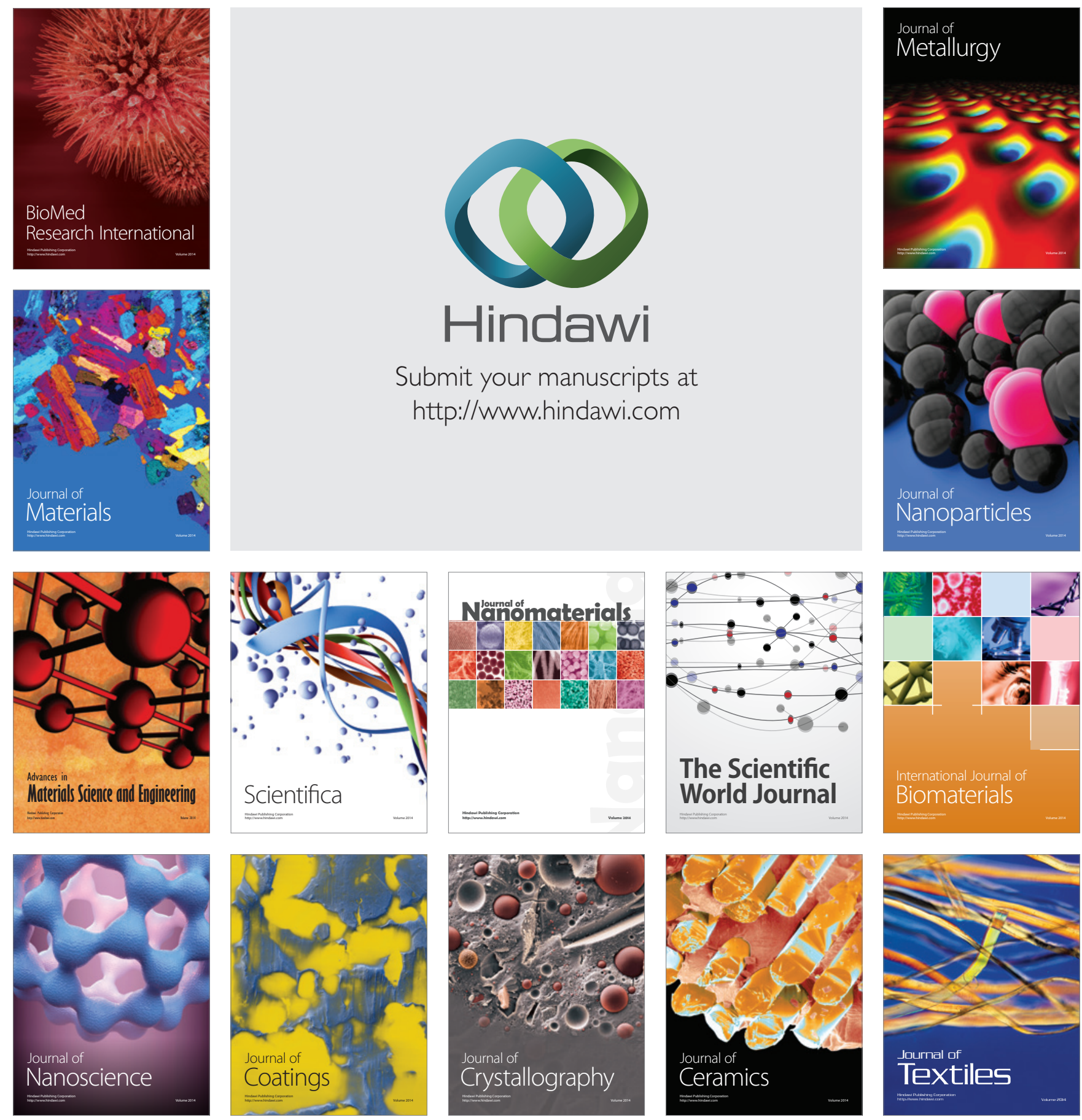